\title{
Study on the Human Resource Management System in Innovative Enterprises
}

\author{
Ruimin $\mathrm{Fu}$ \\ Department of Life Science, \\ Henan institute of education, \\ Zhengzhou, Henan province, P.R.C \\ angelaminmin@163.com
}

\author{
Mingfu Zhu \\ Hebi National Lighting Co. Ltd., \\ Hebi, Henan province, P.R.C
}

The two authors provide equal contribution in this study

\begin{abstract}
Innovative enterprises are faced with the problems of market transformation amid their changing market environment. To adapt to such changes, these enterprises must continuously strengthen their internal management, particularly their human resource management compensation system. These enterprises also have several shortcomings that greatly affect the enthusiasm of their production staff and restrict the development of their potential. By taking Hebi National Lighting Technology Co. Ltd. as an example, this paper analyzes the human resource structure, salary distribution system, and status quo of the enterprise, analyzes its present challenges, and suggests several countermeasures to these problems.
\end{abstract}

Keywords-human resources; salary system; innovative enterprises

\section{INTRODUCTION}

The well-known human resource expert explored the path of global harmonized compensation design and argued that designing an effective global compensation plan could support the operation of companies on a global scale [1-3]. Therefore, the designing of such plan has become a core problem in the management of multinational corporations. Remuneration is a form of return or gratitude given to employees in exchange for their labor. This practice of adding a price to the labor or service of an individual reflects a fair exchange relationship between the employer and the employee. Remuneration may be divided into direct and indirect remuneration. On the one hand, direct remuneration refers to the amount of cash paid to employees, including fixed wages and bonuses. On the other hand, indirect remuneration refers to various forms of payment other than cash, such as in-kind income or treatment. The compensation design of corporations mainly includes three components, namely, wages, bonuses, and benefits.

Strategic compensation management aims to adjust the pay system constantly to adapt to the different stages of corporate strategy [4]. Given that strengthening the match between pay and corporate strategies can increase the efficiency of enterprises, the design of compensation systems can effectively help enterprises gain a competitive advantage in their respective markets.

Strategic compensation system is a forward-looking and competitive salary system made by the enterprise under the strategic sexual force resources management [5-6]. Before designing strategic compensation, enterprise development strategy must be clear. On the basis of this business process, both the internal price bottlenecks and the exhibition department bottlenecks could be straighten out. Moreover, according to the enterprise development strategy and the present situation of the enterprise, the strategic compensation system which is fit for development of enterprise could be built after determining the compensation level and compensation structure of enterprise. Strategic human resource management is a new concept of human resources management in 21st century [7-8]. Strategic compensation management is an important part of strategic human resource management [9-10]. Its success or failure directly relates to not only the success or failure of organization strategic force resources management but also the smooth development of enterprise. Moreover, the development of strategic compensation management can directly related to the enterprise in the fierce market competition in a dominant position. Therefore, how to build a strategic compensation system is the problem that must be solved in the development of modern enterprises [11-12].

The domestic and foreign studies on the design of compensation systems have investigated the maturity of large and medium-sized enterprises and examined the problems in their compensation systems [13-16]. Each pay structure and model has certain advantages, disadvantages, and degrees of adaptability. A mature compensation model can be directly applied by start-up enterprises, growth enterprises, or rapidly developing small- and medium-sized enterprises (SMEs). In this case, how can one design a compensation system that is free from flaws? How can one adjust the remuneration of the use of matching bias? The compensation model must be designed according to the characteristics of each development stage of the enterprise life cycle and combine various elements of compensation to achieve a scientific and effective design.

Employees must be oriented about the principles, purposes, and relevant policies of salary development for them to participate fully in salary-related discussions and acknowledge the fact that their salary is the result of their contributions to the company. However, companies merely design a compensation system in which employees of the same company expect the same value of remuneration. Fair remuneration reflects the 
contribution of managers to the work of their staff as well as fully reflects the pay, incentives, expectations, and respect of companies to their employees. Therefore, an effective remuneration system can guarantee the efficient operation of a company.

The SMEs in China have rapidly developed over the years and have eventually become the main contributors to its economic development and the stable employment of its people. Human resources management has also become the focus of enterprise management. Given the influence of the integrated production capacity of SMEs, companies must improve their compensation mechanisms to obtain high-quality talent.

Growth enterprises are very competitive companies that drive the economic development of China. However, these enterprises have a very weak human resources management and an imperfect compensation system design, which may hinder their continued expansion. The compensation structure of a fast-growing enterprise can be reconstructed, and the compensation design path of a development-oriented enterprise can be expanded. These enterprises may also strengthen their compensation theory and establish a compensation design reference path that can help them recruit effective personnel as well as ensure a long-term, stable, and efficient operation. Therefore, providing compensation incentive guidance has a significant role in the development of growth enterprise.

By taking Hebi National Lighting Technology Co. Ltd. as an example, this paper examines the compensation management system of the enterprise and suggests several countermeasures and solutions to its problems.

\section{RESTRICTION ON INNOVATIVE ENTERPRISES}

The definition of fast-growing enterprises provides the prerequisite and basis for studying these businesses. Rapid growth of the definition of a simple business, that is, with the growth of the enterprise, I believe that the so-called business growth, that is, within a certain period of time from small to large, from weak to strong ability. Some Chinese scholars use the GEP assessment method to define the growth of SMEs. Growth companies sustain their operations for long periods (such as for more than three years) and can continuously tap their unused resources to varying degrees. SMEs are expected to witness excellent development in the future. On this basis, some scholars further define the rapid growth of enterprises by stating that companies will experience rapid development in the long term in terms of their operating efficiency and stability, and that the growth industry will occupy a certain market in the forefront of the contemporary economic development of enterprises.

\section{THE EFFECT OF COOPERATIVE LEARNING OVERVIEW OF HeBi NATiONAL Lighting TECHNOLOGY CO. LTD}

Hebi National Lighting Technology Co. Ltd was founded in 2014 and was named as a national high-tech enterprise in 2016. The enterprise collaborates with Tianjin University and the Chinese Academy of Sciences in building a national, provincial, and municipal R\&D platform, engages in intelligent terminal $\mathrm{R} \& \mathrm{D}$, specializes in LED lighting manufacturing, launches cultural and creative projects, and proposes intelligent solutions for three major industries. Hebi covers a 70 acre land area in the National Photoelectric Park in Hebi City, Henan Province, and is divided into three divisions, namely, the Intelligent Terminal Research Institute (ITI), National LED, and National Lighting. The company mainly produces and sells indoor lighting, outdoor lighting, and creative intelligent light products. Employees of the company receive their salary every month. The company also provides Internet access to homes via intelligent sensing, intelligent decision making, and intelligent control technologies that send the required data to the terminal in real time, thereby ushering the beginning of the smart home era. ITI has independently developed an embedded intelligent terminal that has secured more than 30 patents.

The LED indoor lighting, outdoor lighting, and creative intelligent lighting products of Hebi National Lighting Technology Co. Ltd have received foreign and domestic certifications, including ISO 9001, CCC, FCC, CE, PSE, and RoHs, to guarantee that these products will not harm the vision of their users. These products are also sold in Taobao with a five-year warranty at low prices. Apart from offering lighting products and intelligent solutions, Hebi National Lighting Technology Co. Ltd has launched more than 100 projects related to intelligent transportation, cultural festivals, building illumination, and water conservation. The embedded intelligent terminal research of the company aims to introduce a novel way of accessing the Internet and a new round of revolutions in Internet technology by bringing computers and mobile phones together. In sum, Hebi National Lighting Technology Co. Ltd is a typical fast-growing enterprise in the growth industry.

\section{Human Resource Structure AND SALARY AlLOCATION} SYSTEM OF HEBI NATIONAL Lighting TECHNOLOGY CO. LTD.

\section{A. Human resource structure}

The human resource structure of Hebi National Lighting Technology Co. Ltd mainly serves linear functions. The company has also established several functional departments, such as the Department of Implementation, to implement its management practices. The company focused on the contractor's operating efficiency, total wages and other indicators of control at the same time in the branch, the division within the establishment of the corresponding functional management positions and line management of the team and other institutions, by the branch, the division of internal unity deployment.

\section{B. Salary distribution system}

Hebi National Lighting Technology Co. Ltd adopts a salary distribution management system in which the wages of employees from its several branches are being controlled by the company. Employees of Hebi National Lighting Technology Co. Ltd receive job wages, skills wages, seniority wages, bonuses, and various types of subsidies. The functional management and R\&D personnel of Hebi National Lighting Technology Co. Ltd perform internal quarterly assessments of the firm's salary distribution. The marketing personnel from the marketing department are tasked to increase the rate of payment and monitor the distribution of salaries, while middle 
managers are tasked to assess the distribution of salaries every year.

\section{Problem in the Human Resource Compensation SYSTEM}

\section{A. Human resource architecture}

The upper managers manage the coordination of large workloads. The interface between divisions and the responsibilities of different personnel are unclear. Those individuals who can intervene in the plan are also unknown. Some personnel even ignore the responsibilities of their own departments.

The company does not configure the core of human resources because of the unclear responsibilities among its various departments, making the work of the relevant positions in the company to be further strengthened. The production workshops and planning departments of the firm have not yet established a real-time feedback communication mechanism. All departments are managed and operated according to experience, and Hebi National Lighting Technology Co. Ltd lacks a unified planning, budgeting, and accounting management. The responsibilities of some personnel are unknown because of the unclear job interface. Collaboration within the firm does not follow any fixed rules, thereby resulting in service delays.

Hebi National Lighting Technology Co. Ltd does not have a basic and orderly training mechanism, and various departments within the firm assess the need for temporary training, such as emergency technical training for new employees, based on their own needs. Staff development is excluded from the long-term plans of the company. The human resources department of Hebi National Lighting Technology Co. Ltd has a developed training function that mainly focuses on the induction, skills training, and management training of its employees.

\section{B. Problems in salary allocation problem in salary allocation}

Hebi National Lighting Technology Co. Ltd does not pay its employees regularly and does not have an internal promotion mechanism. A wide salary gap also exists between its old and new employees, much to the dismay of the former. Newcomers are excluded from the leave and pay system of the company until they reach their second year. Unstable people, while production line payment identified, based on historical and practical reasons, the gap between the obvious, can't guarantee internal equity. Compared with the same size module factory, the internal flow is not smooth, sector and job interface is not clear. Many workers assume heavy communication tasks and work overtime. The salaries of some office staff are below the median, and the overall wage level of workers is low. The salary gap between old and new employees also prevents Hebi National Lighting Technology Co. Ltd from guaranteeing internal equity.

The company only has 10 ordinary lines and 2 special lines at the beginning of the year, and offers its employees with two ways of payment. After experiencing some development, Hebi National Lighting Technology Co. Ltd began to offer its auxiliary staff with average wage and improved its payment method. With the growing production needs, and some cable 8 individuals, more than one person on the one sometimes paid by the piece, sometimes by the time, sometimes the average wage, and later, some cable needs 10 individuals, there are changes in payment methods, and then later, for product considerations, some lines today, tomorrow, piece count, more exaggerated is the line in the morning, afternoon piece, the algorithm is very much. Piece-rate employees are sometimes given hourly wages. Complex and varied forms of salary distribution can directly affect the enthusiasm of the production staff. Hebi National Lighting Technology Co. Ltd configures its payroll algorithm based on its business needs, and any department manager has the right to adjust the basic pay structure and amount to be disbursed to the employees. The compensation system of the company changes every year. The complex and variable salary algorithm of Hebi National Lighting Technology Co. Ltd creates a sense of internal injustice that greatly affects the morale of the production staff. The production line workers have no choice but to adjust themselves to the changes in their compensation structure. Comparing the salaries of internal and external workers is not conducive to employee stability. The pay adjustments in the company follow neither a clear decision nor implementation, thereby resulting in unpredictable salaries that affect the performance of the sales staff and the efficiency of the production staff.

The marketing and technical staff members of Hebi National Lighting Technology Co. Ltd work together in manufacturing products or bidding for projects. However, these employees receive different amounts of bonuses because of the various salary distribution methods adopted by the firm. However, other employees receive equal pay despite variations in their production skills because of labor dispatch and other identity differences. Inverted salary is a relatively common phenomenon where workers in subordinate positions receive higher salary than those in managerial positions, where newcomers receive higher salary than the older employees, and operating workers receive higher wages than the managers. This phenomenon greatly affects the enthusiasm of the entire workforce.

The yearly increase in external labor market prices has created a salary gap between the old and new employees of Hebi National Lighting Technology Co. Ltd. The workers from the same industry and from enterprises of the same size also observe a gap in their overall salary levels. Apart from their uncompetitive salary levels, Hebi National Lighting Technology Co. Ltd employees are also denied of any protection or incentives.

\section{SOLUTION TO THE PRoBlems}

\section{A. Clarify the organizational structure and job responsibilities}

All the positions in the company must be analyzed and evaluated by promoting a clear organization structure and clarifying the responsibilities of each employee. These initiatives are also expected to strengthen the links among various posts, promote a rational organization, create an 
effective business process system, balance the responsibilities of various departments, and achieve an ideal working condition.

\section{B. Establish a job competition management system}

The posts, quota, and working hours in the company must be determined based on the available positions in the company. A competitive management system must also be established gradually to promote a rational flow among posts, optimize the allocation of human resources, improve the human resources structure, and enhance the remuneration allocation mechanism to offer the greatest incentives and benefits.

\section{Optimize the distribution of various staff positions}

The mechanism for determining the total wages of various work units must be optimized, and the functional allocation of posts must take into account the average wage level in the industry to develop a reasonable wage distribution mechanism and minimize the salary gap among work units with the same duties and workload. For different types of positions of staff salary distribution, mainly in the bonus distribution mechanism of classification assessment, classification management could be done. In terms of the allocation of fixed posts and the distribution of bonuses, the company may refer to the production and operation status of grassroots units and the sizes of the available work units. Certain bonus policies must also be offered to those workers that manage a large workload and do not meet the required number of posts and quota. Marketing and technical personnel may consider the reference project management mode, form a product sales project team, and determine the bonus distribution program based on the order amount. The technical research personnel must also consider the flexible and reasonable allocation of various assessment methods, such as approving and initiating a project as well as contracting the project cost.

\section{Improve the human resources recruitment and training system}

The cooperation with professional human resources must be strengthened according to the actual situation of the market pay system, the timely adjustment of the salary distribution system, the internal distribution of salaries, and the current salary level in the market. The company must adopt a secure pay and benefits system and offer special posts to its special talents.

\section{CONCLUSION}

The establishment of an effective compensation system is directly related to the smooth development of enterprises, and configuring a reasonable and sound human resource management can effectively promote the growth of an enterprise. Enterprises in the photo voltaic industry may also achieve growth by establishing reasonable and sound human resource management and compensation systems. However, these systems must take several factors into consideration. First, the human resource management structure must be re-planned to achieve a clear division of responsibility among the workers in the enterprise. Second, a high-performance culture of professionalism must be bred within the firm by awarding the employees for their merits and punishing them for their faults. Third, the employment mechanism must be open, and the relationship between young and old employees must be strengthened. Fourth, a talent echelon must be established, and firms must complement their recruitment of external employees in the short term with the cultivation of internal talents in the long term. These recommendations may help enterprises configure and improve their compensation systems.

\section{REFERENCES}

[1] Noe R A, Hollenbeck J R, Gerhart B, et al. Human resource management: Gaining a competitive advantage[J]. 2006.

[2] Gupta N, Shaw J D. Employee compensation: The neglected area of HRM research[J]. Human Resource Management Review, 2014, 24(1): $1-4$.

[3] Collings D G. Integrating global mobility and global talent management: Exploring the challenges and strategic opportunities[J]. Journal of World Business, 2014, 49(2): 253-261.

[4] Berber N, Morley M J, Slavić A, et al. Management compensation systems in Central and Eastern Europe: a comparative analysis[J]. The International Journal of Human Resource Management, 2017: 1-29.

[5] Osibanjo A O, Adeniji A A, Falola H O, et al. Compensation packages: a strategic tool for employees' performance and retention[J]. Leonardo Journal of Sciences, 2014 (25): 65-84.

[6] Thompson J, Berk M, O’Donnell M, et al. Attributions of responsibility and recovery within a no-fault insurance compensation system[J]. Rehabilitation psychology, 2014, 59(3): 247.

[7] Junni P, Sarala R M, Tarba S Y, et al. Guest editors' introduction: The role of human resources and organizational factors in ambidexterity[J]. Human Resource Management, 2015, 54(S1): s1-s28.

[8] Bruce Tracey J. A review of human resources management research: The past 10 years and implications for moving forward[J]. International Journal of Contemporary Hospitality Management, 2014, 26(5): 679-705.

[9] Menz M, Scheef C. Chief strategy officers: Contingency analysis of their presence in top management teams[J]. Strategic Management Journal, 2014, 35(3): 461-471.

[10] Jackson S E, Schuler R S, Jiang K. An aspirational framework for strategic human resource management[J]. The Academy of Management Annals, 2014, 8(1): 1-56.

[11] Gupta N, Shaw J D. Employee compensation: The neglected area of HRM research[J]. Human Resource Management Review, 2014, 24(1): $1-4$

[12] Xavier B. Shaping the future research agenda for compensation and benefits management: Some thoughts based on a stakeholder inquiry[J]. Human resource management review, 2014, 24(1): 31-40.

[13] Liu F, Maitlis S. Emotional dynamics and strategizing processes: A study of strategic conversations in top team meetings[J]. Journal of Management Studies, 2014, 51(2): 202-234.

[14] Krishnan A, Ramasamy R, Joshi P L. An empirical study of nonfinancial measures' emphasis for the compensation schemes on different categories of strategic orientation in Malaysia[J]. Indian Journal of Finance, 2014, 8(12): 7-20.

[15] Liu F, Maitlis S. Emotional dynamics and strategizing processes: A study of strategic conversations in top team meetings[J]. Journal of Management Studies, 2014, 51(2): 202-234.

[16] Sikora D M, Ferris G R. Strategic human resource practice implementation: The critical role of line management[J]. Human Resource Management Review, 2014, 24(3): 271-281. 